\title{
Comparação entre Redes Neurais Artificiais e Regressão Linear Múltipla para estimar radiação solar no município de Seropédica - RJ
}

\section{Comparison between Artificial Neural Networks and Multiple Linear Regression to estimate solar radiation in the city of Seropédica - $R J$}

Erylaine Reis Rubim Moreira Araujo1, Robson Mariano da Silva²

\section{RESUMO}

O presente estudo propõe o desenvolvimento e avaliação de uma metodologia utilizando Redes Neurais Artificiais (RNAs) para estimar a incidência de radiação solar em Seropédica - RJ. Primeiramente foi avaliada a necessidade de se utilizar todos os dados disponibilizados pelo Instituto Nacional de Meteorologia. Em seguida foram realizados experimentos variando o número de neurônios na(s) camada(s) escondida(s). Diferentes parâmetros estatísticos foram utilizados para avaliar 0 desempenho dos modelos ( $r$, MAE, RMSE, D, R2, C e skill). Os modelos de RNAs foram comparados com Regressão Linear Múltipla (RLM) para verificar qual método seria satisfatório. Como resultado, foi possível constatar que não há necessidade de utilizar todas as variáveis disponibilizadas pela estação. Analisando a média das 50 simulações realizadas, foi possível verificar também que a RNA cujo desempenho foi superior contava com apenas uma camada escondida, apresentando índice de confiança médio (D) de $88 \%$ e coeficiente de determinação médio $\left(R^{2}\right)$ de $85 \%$. Mesmo mostrando-se superiores, os modelos de RNAs não apresentaram ganhos significativos frente aos modelos de RLM. Assim, foi possível concluir que RNAs é uma ferramenta adequada para estimar a incidência de radiação solar.

Palavras-chave: Radiação solar. Redes Neurais Artificiais. Regressão Linear Múltipla.

\section{ABSTRACT}

The present study aims the development and evaluation of a methodology using Artificial Neural Networks (ANNs) to estimate the incidence of solar radiation in Seropédica - RJ. Firstly, the need of using all the data provided by the National Institute of Meteorology was assessed. Then experiments were performed by varying the number of neurons in the hidden layer. Different statistical parameters were used to evaluate the performance of the models ( $r, M A E, R M S E, D, R 2, C$ and skill). The RNA models were compared with Multiple Linear Regression (MLR) to verify which method would be satisfactory. As a result, it was possible to find that there is no need to use all the variables available. Analyzing the average of the 50 simulations performed, it was also possible to verify that the RNA whose performance was superior had only one hidden layer, with an average confidence index (D) of $88 \%$ and an average determination coefficient $\left(\mathrm{R}^{2}\right)$ of $85 \%$. Even though they were superior, the RNA models did not show significant gains compared to MLR models. Thus, it was possible to conclude that ANNs are a suitable tool for solar radiation estimation.

Keywords: Solar Radiation. Artificial Neural Networks. Multiple Linear Regression.
Mestranda em Modelagem Matemática e Computacional. Universidade Federal Rural do Rio de Janeiro

E-mail: erylaine@hotmail.com

Doutor em Engenharia. Biomédica. Universidade Federal do Rio de Janeiro 


\section{INTRODUÇAOO}

Nos últimos anos a demanda por energia elétrica aumentou drasticamente, pois se tornou fundamental para a vida cotidiana e para a economia. A Energia elétrica proveniente de combustíveis fósseis ou de hidrelétricas gera um grande impacto ambiental, seja pelo agravamento do efeito estufa, a poluição do ar, ou por causar alagamento de grandes áreas, interferindo na vegetação e fauna local, entre outros (COSTA, 2016). Na busca por formas de geração de energia que menos agridam ao meio ambiente, que reduzam as emissões de gases de efeito de estufa, além da perspectiva de esgotamento do petróleo nas próximas décadas (Bentley, 2002) pode-se citar a energia solar como uma alternativa de energia renovável. Existe também a necessidade de expandir a credibilidade e a segurança do setor energético de uma nação e para isso, diversificar a matriz energética é uma boa forma de precaver possíveis imprevistos, como por exemplo, a geração de energia hidroelétrica possui inconstância em decorrência dos longos períodos de estiagem comuns no Brasil (FIORIN ET.AL., 2011).

Metodologias aplicando Redes Neurais Artificiais (RNAs) estão sendo desenvolvidas e utilizadas para avaliação e previsão da disponibilidade de recursos de energia solar, como é o caso de Coutinho (2016) que fez uso de Redes Neurais Artificiais do tipo Perceptrons de Múltiplas Camadas (MLP) e Função de Base Radial (RBF) para realizar a predição de um passo à frente em séries de dados meteorológicos. Além disso, realizou a comparação de tais métodos com modelos de Regressão Linear Múltipla (RLM) onde comprovou que as RNAs MLP e RBF são mais adequadas para tal estudo, pois suas estimativas foram consideravelmente próximas aos dados reais. Mendes et.al. (2017) utilizou as medições de dados meteorológicos provenientes do Sistema de Organização Nacional de Dados Ambientais (SONDA) para predizer a radiação de energia solar global através das Redes Neurais. Como resultado obteve que as Redes Neurais são uma boa ferramenta para previsão de dados de modelos com características não lineares e obteve êxito na previsão de radiação solar global.

Devido o Brasil estar localizado em uma região tropical e subtropical, recebe elevada irradiação solar durante todo o ano, o que propicia a utilização desse tipo de energia. $O$ potencial de geração fotovoltaica no Brasil é tão grande que, no local com menos incidência de radiação solar no país, é possível gerar mais eletricidade solar do que no local com maior incidência de radiação solar da Alemanha, por exemplo. (PEREIRA et. al., 2017). 
De acordo com o Instituto de Pesquisa Econômica Aplicada (IPEA, 2019) a capacidade instalada no Brasil aumentou consideravelmente nos últimos dois anos, crescendo de $0,1 \%$ para $1,4 \%$ de 2016 a 2018. Entre esses dois anos, aproximadamente 41 mil novas usinas de energia solar foram instaladas no Brasil. Houve um aumento significativo no número de estabelecimentos comerciais, industriais e residenciais que passaram a produzir e consumir dessa fonte de energia. Este aumento se dá em virtude de vários fatores, como a diminuição nos custos de fabricação, o aumento na eficiência dos módulos fotovoltaicos e a facilidade na implementação de sistemas de pequeno e grande porte, no entanto o país ainda está em seus passos iniciais na geração de energia solar fotovoltaica. (ABDALA, 2019)

Seropédica é um município do estado do Rio de Janeiro que se localiza aproximadamente $70 \mathrm{~km}$ da capital. De acordo com o Instituto Brasileiro de Geografia e Estatística (IBGE, 2017) sua área é de 283,762km2. No último censo em 2010 sua população foi de 78.186 pessoas, garantindo a $31^{\text {a }}$ posição no ranking dos 92 municípios

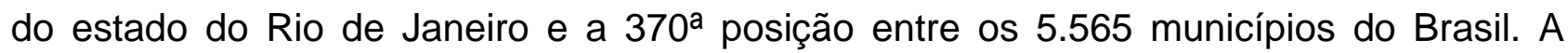
estimativa populacional para 2018 foi de 86.743 pessoas e sua densidade demográfica é $275,53 \mathrm{hab} / \mathrm{km}^{2}$.

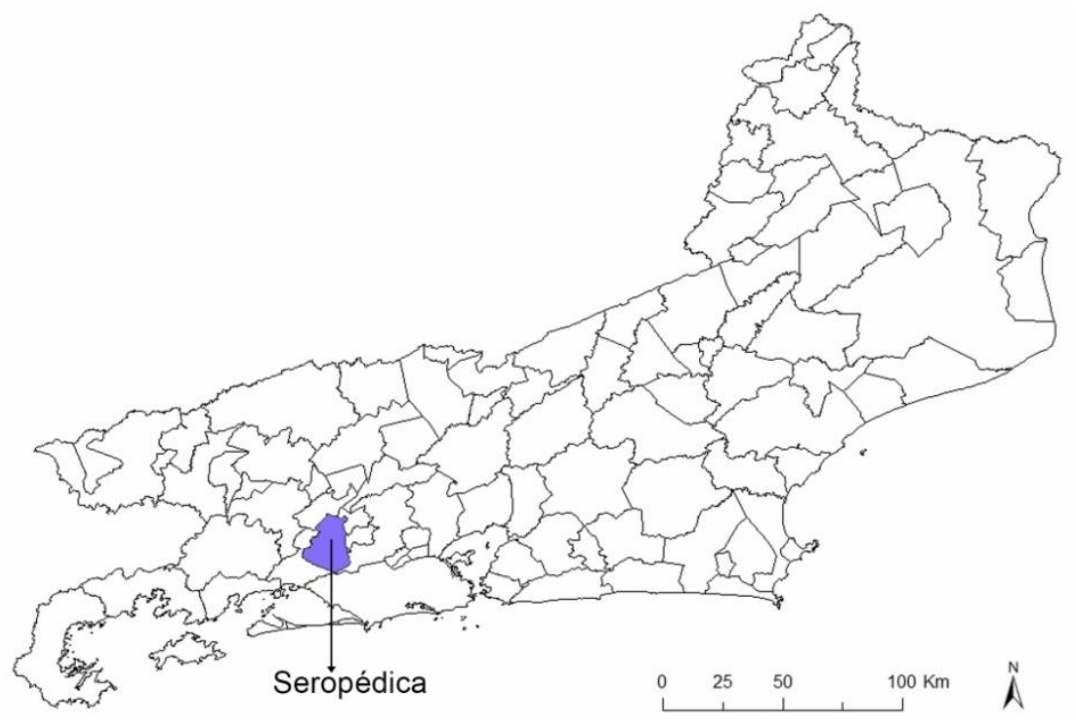

Figura 1. Mapa do Rio de Janeiro com a região de estudo

As principais atividades econômicas da região são o comércio, a extração de mineral e a indústria (PMS, 2019). Em 2016 o PIB per capta de Seropédica foi de $\mathrm{R} \$ 24.602,97$. (IBGE, 2017).

De acordo com o Instituto Nacional de Meteorologia (INMET) a temperatura média compensada anual em Seropédica é de $23,80^{\circ} \mathrm{C}$. Para a Fundação Instituto de 
Desenvolvimento Econômico e Social do Rio de Janeiro (FIDERJ, 1978, apud Castro et.al. 2009) o clima é subúmido e mesotérmico com calor bem distribuído ao longo do ano.

Devido ao fato da população e da economia local estar em crescimento, consequentemente haverá o aumento no consumo de energia elétrica. A região é propícia a exploração da energia solar, fato este que justifica a escolha da área de estudo para o presente trabalho.

Os modelos numéricos que são utilizados em previsão meteorológica possuem códigos computacionais para parametrização dos processos radiativos na atmosfera e podem ser utilizados para previsão da irradiação solar na superfície. Porém, as previsões fornecidas por tais modelos, apresentam desvios elevados em relação a valores medidos em superfície para um ou dois dias de antecedência (HEINEMANN, 2004). Estudos indicam como principal motivo desses desvios elevados a dependência da irradiação solar em relação às condições meteorológicas que envolvem intrinsecamente processos físicos não-lineares de difícil parametrização (MESINGER, 2005).

Assim, o presente trabalho é um estudo sobre previsão de radiação solar incidente diária no Município de Seropédica, objetivando principalmente fornecer informações que atendam as atividades ligadas à geração de energia. Para isso utilizou-se o método computacional conhecido como Redes Neurais Artificiais (RNAs) pela sua notória capacidade de reconhecimento de padrões, além de gerar bons resultados para problemas que apresentam alto grau de não-linearidade. Foi feito também uma comparação com o método de Regressão Linear Múltipla (RLM) a fim de analisar qual método apresentaria melhores resultados.

Após a introdução, o artigo está organizado nas seguintes seções: Seção 2 descreve os materiais e métodos utilizados na presente pesquisa, a Seção 3 apresenta os resultados e discussões obtidos e a Seção 4 mostra as conclusões do estudo.

\section{MATERIAIS E METODOS}

O propósito da presente seção é descrever as etapas que foram realizadas no trabalho proposto, desde a obtenção e preparação dos dados aos parâmetros de avaliação do desempenho dos modelos. 
A área de estudo e investigação da pesquisa compreende os dados obtidos do Instituto Nacional de Meteorologia (INMET). A estação selecionada para o levantamento de dados do presente estudo faz parte da rede de Estações Meteorológicas Automáticas (EMA), a estação Ecologia Agrícola (A601), situada no município de Seropédica (Latitude:

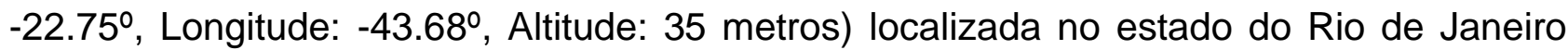
(RJ).

Os dados foram selecionados no período de 01 de Maio de 2017 a 31 de Janeiro de 2019, no horário compreendido entre 10h e 20h (hora UTC), devido a corresponder a um período significativo de incidência de radiação solar.

As informações meteorológicas da EMA são coletadas por minuto e estes dados são integralizados a cada hora. A partir destes dados, depois da seleção dos horários de interesse para o presente estudo, foram obtidas através da formação de rotinas computacionais as médias diárias de cada uma das variáveis. Optou-se por fazer as médias diárias para evitar a ocorrência de grandes erros, visto que isso ocorreria caso fossem utilizadas todas as medições horárias coletadas.

Após a obtenção das médias diárias os dados foram normalizados a fim de melhorar a eficiência do treinamento da rede. Dessa forma, tanto as variáveis de entrada como as de saída assumem valores entre 0 e 1. É calculado através da equação (Perboni et.al., 2014):

$$
x_{\text {norm }}=\frac{x_{0}-x_{\min }}{x_{\max }-x_{\min }}
$$

Onde: $x_{n o r m}$ é a variável normalizada, $x_{0}$ a variável original, $x_{\max } 0$ valor máximo observado entre as variáveis e Xmin o valor mínimo observado entre as variáveis.

$\mathrm{Na}$ tabela 1 é possível visualizar o resumo dos dados que foram utilizados pelo modelo, e também um exemplo de um dos conjuntos de treinamento e teste utilizados. Realizadas essas etapas, os dados estavam aptos para serem utilizados pelas redes neurais.

Os dados foram divididos randomicamente em $80 \%$ para treinamento e $20 \%$ para teste. É importante ressaltar que mesmo sendo selecionados randomicamente, os dados dos conjuntos de treinamento e teste possuem amostras igualmente distribuídas, consistindo assim numa divisão homogênea de todo o conjunto de dados.

Tabela 1. Resumo do conjunto de dados e de um dos subconjuntos de treinamento e teste 


\begin{tabular}{|c|c|c|c|c|c|c|c|c|c|c|c|}
\hline & & Radiação & Temp_Inst. & Temp_Max. & Temp_Min. & Umi_Inst. & Umi_Max. & Umi_Min. & $\begin{array}{c}\text { Pto. } \\
\text { Orv_Max. }\end{array}$ & $\begin{array}{c}\text { Pto. } \\
\text { Orv_Min. }\end{array}$ & Vel_vento \\
\hline \multirow{6}{*}{ 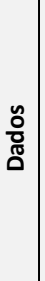 } & Mínimo & 146.9 & 17.36 & 17.55 & 16.94 & 26.27 & 29.45 & 24.55 & 9.491 & 7.745 & 0.6364 \\
\hline & 1ㅇ Quartil & 1049.8 & 23.42 & 24.02 & 22.36 & 52.18 & 57.55 & 49.09 & 16.309 & 14.691 & 2.0000 \\
\hline & Mediana & 1440.2 & 26.18 & 26.87 & 25.23 & 61.91 & 66.73 & 58.45 & 18.709 & 17.218 & 2.6727 \\
\hline & Média & 1480.0 & 26.26 & 26.89 & 25.27 & 62.00 & 66.52 & 58.97 & 18.438 & 16.909 & 2.7022 \\
\hline & 3 Quartil & 1976.8 & 28.78 & 29.59 & 27.75 & 71.09 & 75.27 & 67.91 & 20.700 & 19.282 & 3.3182 \\
\hline & Máximo & 2686.1 & 34.85 & 35.77 & 33.69 & 93.18 & 93.73 & 92.45 & 24.245 & 22.800 & 5.8273 \\
\hline \multirow{6}{*}{ 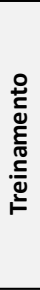 } & Mínimo & 146.9 & 17.36 & 17.55 & 16.94 & 26.27 & 29.45 & 24.55 & 9.491 & 7.745 & 0.6364 \\
\hline & 19 Quartil & 1049.8 & 23.40 & 24.00 & 22.34 & 52.18 & 57.55 & 49.09 & 16.309 & 14.745 & 2.0000 \\
\hline & Mediana & 1438.2 & 26.13 & 26.85 & 25.15 & 62.00 & 67.00 & 58.36 & 18.682 & 17.164 & 2.6909 \\
\hline & Média & 1473.8 & 26.20 & 26.83 & 25.20 & 62.06 & 66.00 & 59.03 & 18.396 & 16.865 & 2.7077 \\
\hline & 3ㅇ Quartil & 1976.8 & 28.77 & 29.60 & 27.67 & 71.18 & 75.55 & 68.09 & 20.700 & 19.227 & 3.3182 \\
\hline & Máximo & 2686.1 & 34.85 & 35.77 & 33.69 & 93.18 & 93.73 & 92.45 & 24.245 & 22.800 & 5.8273 \\
\hline \multirow{6}{*}{ 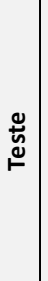 } & Mínimo & 328.9 & 18.37 & 18.89 & 18.02 & 29.00 & 32.73 & 27.36 & 10.71 & 8.855 & 0.6545 \\
\hline & 19 Quartil & 1058.0 & 23.50 & 24.26 & 22.47 & 52.48 & 57.91 & 49.45 & 16.51 & 14.618 & 2.0068 \\
\hline & Mediana & 1440.3 & 26.47 & 27.20 & 25.81 & 61.50 & 66.73 & 58.50 & 19.05 & 17.550 & 2.5864 \\
\hline & Média & 1505.2 & 26.48 & 27.13 & 25.51 & 61.77 & 66.21 & 58.76 & 18.61 & 17.088 & 2.6806 \\
\hline & 3 Quartil & 1955.3 & 28.93 & 29.49 & 28.03 & 70.52 & 74.43 & 67.34 & 20.91 & 19.579 & 3.2559 \\
\hline & Máximo & 2639.6 & 34.50 & 35.08 & 33.35 & 91.00 & 92.00 & 89.91 & 23.68 & 22.391 & 5.1000 \\
\hline
\end{tabular}

\subsection{Seleção dos Grupos de Preditores}

A estação Ecologia Agrícola oferece dados como temperatura, umidade, ponto de orvalho, pressão atmosférica, direção e velocidade dos ventos, precipitação e radiação solar. Para as variáveis temperatura, umidade, ponto de orvalho e pressão atmosférica, são disponibilizadas medições instantâneas, máximas e mínimas, ao todo são 16 variáveis que podem ser utilizadas como preditores de radiação solar.

A fim de otimizar o grupo de preditores objetivando selecionar as variáveis que mais contribuíssem para a predição de radiação solar, foram realizados experimentos utilizando Regressão Linear através do software $R$, com a função glm. Por meio dessa função foram obtidos as estimativas pontuais, os erros padrão das estimativas pontuais e o nível de significância ( $p)$. Foi adotado um nível de significância de $5 \%(p<0,05)$, ou seja, um intervalo de confiança de $95 \%$. Nessa etapa foram evidenciadas as variáveis que apresentaram um nível de significância superior a 5\%.

Logo em seguida iniciaram-se os experimentos com RNA. O primeiro experimento contou com as 16 variáveis disponibilizadas, e a partir daí as variáveis com $p>0,05$ foram excluídas do modelo uma a uma.

De acordo com Guarnieri (2006), para redes que possuem um grande número de entradas, determinadas topologias levam a resultados incoerentes ou até resultados negativos de radiação. Assim para um grupo de preditores com muitas entradas, o autor 
sugere a topologia para o treinamento das RNAs a estrutura RNA-(n)-(n)- $(0,5 n)-1$, onde $n$ é o número de neurônios, portanto nesta etapa do trabalho a recomendação do autor foi seguida.

Em todos os experimentos para cada topologia da RNA foram repetidas 50 simulações, concomitantemente para cada conjunto de treino e teste/validação, usou-se RLM para fins de comparação. Nesta etapa a RLM foi utilizada como uma ferramenta norteadora dos ajustes das variáveis preditoras, ficando como critério de seleção das mesmas a análise dos Índices: Índice de Confiança (C), Erro Médio Absoluto (MAE Mean Absolute Error) e Raiz do Erro Médio Quadrático (RMSE - Root Mean Squared Error).

\subsection{Treinamento da RNA}

A metodologia adotada foi a de RNA do tipo Perceptron de múltiplas camadas (MLP). Com o intuito de identificar qual topologia seria mais adequada, a partir dessa etapa o presente estudo foi dividido em dois subgrupos de teste. Ambos consistiram em realizar experimentos variando o número de neurônios na camada escondida, assim, no primeiro foram treinadas redes compostas apenas por uma camada interna e no segundo redes compostas por duas camadas internas.

O próximo passo foi definir quais variáveis seriam utilizadas na entrada da rede. Como citado no item anterior as variáveis: temperatura, umidade, ponto de orvalho e pressão atmosférica, possuíam medições instantâneas, máximas e mínimas. Assim foram feitos testes utilizando cada uma dessas medições individualmente e também com todas de uma vez a fim de verificar qual geraria melhor resultado. Com o intuito de facilitar a referência aos experimentos realizados, uma nomenclatura personalizada foi adotada:

- Modelo completo: experimento que utiliza todas as variáveis preditoras indicadas como relevantes para predição de radiação solar.

- Modelo instantâneo: experimento que utiliza as medições instantâneas das variáveis preditoras indicadas como relevantes para predição de radiação solar.

- Modelo máximo: experimento que utiliza as medições máximas das variáveis preditoras indicadas como relevantes para predição de radiação solar.

- Modelo mínimo: experimento que utiliza as medições mínimas das variáveis preditoras indicadas como relevantes para predição de radiação solar.

Logo em seguida os dados foram divididos em conjuntos de treinamento e teste. $O$ software $\mathrm{R}$ foi programado para dividir randomicamente o conjunto de dados em $80 \%$ 
para treinamento da rede e os $20 \%$ restante foram reservados para a teste/validação do modelo.

Após as simulações de diversas topologias para investigação de qual seria a mais adequada, foi feito um estudo sobre o comportamento do erro MAE a fim de verificar a necessidade de se realizar simulações de outras topologias além das inicialmente propostas. A tabela 2 apresenta um resumo dos parâmetros utilizados pelo modelo proposto.

Tabela 2. Resumo dos parâmetros do modelo proposto

\begin{tabular}{|c|c|}
\hline Parâmetros & Valor \\
\hline № de simulações por arquitetura & 100.000 iterações \\
\hline № máximo de épocas & Logística \\
\hline Função de ativação & Falsa \\
\hline Likelihood & 1 \\
\hline № de repetições da rede no treinamento & Resilient backpropagation \\
\hline Algoritmo de treinamento & Randomico \\
\hline Inicialização dos pesos & 0,01 \\
\hline Threshold (critério de parada) & SSE (Sum of Squared Errors) \\
\hline Métrica usada erro de treinamento &
\end{tabular}

Fazendo uso do mesmo conjunto de dados de entrada, foram calculadas regressões lineares múltiplas (RLMs) para fins de comparação com os resultados da RNA.

Por causa da normalização dos dados, os resultados das RNAs do presente estudo pertencem ao intervalo de 0 a 1. Logo, para poder analisar tais resultados foi indispensável realizar o procedimento de desnormalização dos dados, ou seja, tornar os valores para a escala real, conforme a seguinte equação (Coutinho, 2014):

$$
V_{j}=\left(x_{j} * x_{\max }\right)-\left(x_{j} * x_{\min }\right)+x_{\min }
$$

Onde $V_{j}$ é a variável desnormalizada, $x_{j}$ variável predita pela rede, $x_{\max } 0$ valor máximo observado entre as variáveis e Xmin o valor mínimo observado entre as variáveis.

Após as simulações das redes e avaliar as estruturas com diferentes quantidades de neurônios nas camadas ocultas, a arquitetura mais adequada foi determinada. A primeira análise foi avaliar qual dentre os modelos (completo, instantâneo, máximo ou mínimo) geraria melhores resultados. Posteriormente foi feita uma análise entre as redes que possuíam o mesmo número de camadas, selecionando também as que apresentariam 
melhores resultados e por fim foram comparadas as melhores redes com uma e duas camadas escondidas.

\subsection{Avaliações das Previsões}

Para comparar o desempenho dos modelos foram utilizadas diferentes medidas estatísticas, que geralmente são utilizadas na literatura, além de também serem descritas por vários autores (Pezzopane et al., 2012; Guarnieri, 2006; Deshmukh e Ghatol, 2010; Fonseca et al., 2012), são elas:

\section{- Coeficiente de Correlação de Pearson (r):}

Por definição o coeficiente de correlação representa uma medida do grau de dependência linear entre duas variáveis, que no presente estudo são os valores estimados pela rede (xj) e os valores observados pela estação (Oj) é calculado por:

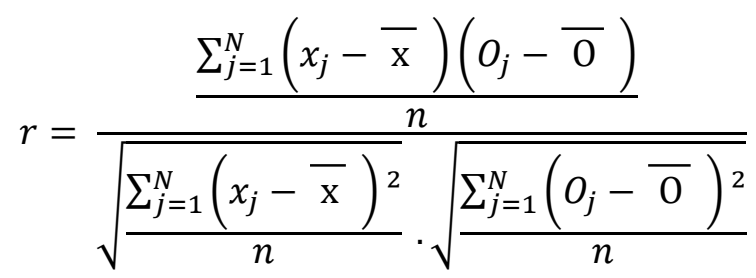

Onde $\overline{\mathrm{x}}$ é a média dos valores estimados e $\overline{\mathrm{O}}$ é a média dos valores observados e $\mathrm{n}$ representa o número de dados utilizados. O resultado do coeficiente de correlação varia no intervalo de $[-1,1]$, onde 1 representa que existe uma correlação linear positiva perfeita entre $x_{j}$ e $\mathrm{O}_{j}$.

\section{- Erro Médio Absoluto (MAE - Mean Absolute Error):}

Através do MAE é possível obter a magnitude média dos erros de previsão. $O$ resultado varia no intervalo de $[0, \infty)$ onde 0 representa o valor para a previsão perfeita. É calculado através da seguinte equação:

$$
M A E=\frac{\sum_{j=1}^{n}\left|O_{j}-x_{j}\right|}{n}
$$

\section{- Raiz do Erro Médio Quadrático (RMSE - Root Mean Squared Error):}

É o valor que representa a magnitude média dos erros de previsão. O resultado varia no intervalo de $[0, \infty)$ onde 0 representa o valor para a previsão perfeita. É obtido por:

$$
R M S E=\sqrt{\frac{\sum_{j=1}^{n}\left(O_{j}-x_{j}\right)^{2}}{n}}
$$

\section{- Índice de Concordância (D):}


Fornece o grau de exatidão entre as variáveis envolvidas, pois relaciona a diferença entre os valores estimados em relação aos valores observados. $O$ resultado varia no intervalo de $[0,1]$ onde 0 representa nenhuma concordância e 1 significa que houve uma concordância perfeita.

$$
D=1-\frac{\sum_{j=1}^{n}\left(o_{j}-x_{j}\right)^{2}}{\sum_{j=1}^{n}\left(\left|x_{j}-\overline{0}\right|+\left|o_{j}-\overline{0}\right|\right)^{2}}
$$

\section{- Coeficiente de Determinação $\left(R^{2}\right)$ :}

$O \mathrm{R}^{2}$ é uma medida que descreve a qualidade do ajuste do modelo. Seu resultado varia de 0 a 1, representado de 0 a 100\% da variância total das observações explicadas pelos valores estimados. Sua equação é dada por:

$$
R^{2}=\frac{\sum_{j=1}^{N}\left(x_{j}-\overline{0}\right)^{2}}{\sum_{j=1}^{N}\left(O_{j}-\overline{0}\right)^{2}}
$$

\section{- Índice de Confiança (C):}

Através do índice de confiança, é possível analisar simultaneamente a precisão e a exatidão dos resultados obtidos. Ele é calculado através do produto do coeficiente de correlação (r) pelo índice de concordância:

$$
C=(r * D)
$$

Seus valores variam no intervalo de $[0,1]$ onde zero representa que não há nenhuma concordância e 1 representa a concordância perfeita (Pezzopane et. al., 2012). A Tabela 3 demonstra os critérios para avaliação de desempenho.

Tabela 3. Critérios para avaliação e análise do desempenho de modelos com base no índice de confiança

\begin{tabular}{|c|c|}
\hline Valor de C & Desempenho \\
\hline$>0,85$ & Ótimo \\
\hline 0,76 a 0,85 & Muito bom \\
\hline 0,66 a 0,75 & Bom \\
\hline 0,61 a 0,65 & Mediano \\
\hline 0,51 a 0,60 & Sofrível \\
\hline 0,41 a 0,50 & Mau \\
\hline$\leq 0,40$ & Péssimo \\
\hline
\end{tabular}

\section{- Skill:}


Este índice é utilizado para comparar dois modelos em termos de ganho (ou aperfeiçoamento), é obtido relacionando um modelo a outro adotado como referência. Sua fórmula é dada por:

$$
\operatorname{Skill(ÍNDICE,ref)}=\frac{\text { ÍNDICE }- \text { ÍNDICE } E_{r e f}}{\text { INNDICE } E_{p e r f}-\mathbf{I} N D I C E_{r e f}}
$$

onde ÍNDICE pode assumir qualquer um dos índices anteriormente citados, ÍNDICE $E_{\text {perf }}$ é o valor onde este índice assume a previsão perfeita, ou seja, assume o valor 0 para erros como MAE ou RMSE e assume o valor 1 para $\mathrm{r}$, D ou $\mathrm{R}^{2}$, ÍNDICE $E_{\text {ref }}$ é o valor deste índice calculado para uma outra previsão adotada como referência.

Quando o Skill assume valor igual a 1 representa que a previsão atingida foi perfeita, quando se iguala a 0 significa que não houve ganho se comparado a previsão de referência e por fim, quando se obtém valores negativos quer dizer que a previsão avaliada é inferior a previsão de referência.

\section{RESULTADOS E DISCUSSÄO}

Nesta seção são exibidos e discutidos os resultados alcançados pelos modelos aplicados no presente estudo.

\subsection{Seleção dos Grupos de Preditores}

Como mencionado anteriormente, a estação Ecologia Agrícola fornece dados que podem ser utilizados como conjunto de preditores de radiação solar como temperatura (instantânea, máxima, mínima), umidade (instantânea, máxima, mínima), ponto de orvalho (instantâneo, máximo, mínimo), pressão atmosférica (instantânea, máxima, mínima), vento (velocidade, rajada, direção) e chuva.

Inicialmente todas as 16 variáveis preditores foram utilizadas, a partir daí, foram realizados experimentos excluindo os grupos: chuva, pressão atmosférica instantânea, pressão atmosférica máxima, pressão atmosférica mínima, direção dos ventos, rajada dos ventos, ponto de orvalho instantâneo, temperatura máxima e umidade instantânea respectivamente.

Os índices utilizados como critério de seleção nesta etapa, foram utilizados por serem índices que evidenciam a precisão e a exatidão dos resultados além de representam a magnitude média dos erros de previsão. Os erros MAE e RMSE mensuram 
o tamanho médio dos módulos dos desvios entre previsões e observações, a diferença entre ambos é que enquanto o MAE é a média aritmética dos módulos dos desvios, o RMSE representa uma média quadrática dos desvios, pode-se pensar nele como uma medida análoga ao desvio padrão.

Dos dados obtidos nas 50 simulações realizadas, foram calculadas as médias tanto para a RNA como para RLM. Foram selecionados também os casos que apresentaram índice de Confiança (C) máximo e mínimo, conforme mostra a tabela 4. Ao analisar a tabela observou-se que em alguns casos, os experimentos mostraram-se bastante similares entre si, houve casos onde a RLM mostrou desempenho superior a RNA.

É importante notar que, embora para alguns dos experimentos a média seja aparentemente boa, analisando os valores máximos e mínimos atingidos pela RNA nas 50 simulações realizadas, observa-se que em todos os casos os valores máximos de $C$ apresentam desempenho ótimo $(C>0,85)$, entretanto ao analisar os valores mínimos obtidos, em alguns dos casos apresentaram desempenho sofrível $(0,51$ a 0,60$)$, mau $(0,41$ a 0,50$)$ ou até mesmo péssimo $(C \leq 0,40)$.

Após uma análise detalhada das médias obtidas nos experimentos, foi possível verificar e definir o caso onde os melhores resultados foram encontrados, (maior Índice de Confiança e menores MAE e RMSE). Assim o experimento que contava com 9 preditores (temperatura (instantânea, máxima, mínima), umidade (instantânea, máxima, mínima), ponto de orvalho (máximo, mínimo) e velocidade do vento) foi o mais indicado para ser usado no treinamento das RNAs. Foi observado também que em termos do Índice de Confiança, dentre as 50 simulações realizadas, o valor mínimo obtido apresentou desempenho muito bom $(0,76$ a 0,85$)$, o valor máximo e a média apresentaram ótimo desempenho $(C>0,85)$.

Nesta etapa foi possível notar que excetuando os casos onde a RLM mostrou-se superior a RNA, nos demais experimentos a RNA superou a RLM, houve também uma melhora significativa no modelo com a redução das variáveis de 16 para 9 preditores, constatando que de fato existem variáveis que podem ser excluídas do mesmo. Além disso, verificou-se que as 9 variáveis preditoras selecionadas possuem informação suficiente para gerar uma boa estimativa de radiação solar incidente em Seropédica. 
DOI: 10.18605/2175-7275/cereus.v12n2p210-232

Revista Cereus

2020 Vol. 12. N.2
ARAUJO, E.R.R.M., SILVA, R.M.

Comparação entre Redes Neurais Artificiais e Regressão Linear Múltipla para estimar radiação solar no município de Seropédica RJ.

Tabela 3. Índices de avaliação calculados na seleção das variáveis preditora

\begin{tabular}{|c|c|c|c|c|c|}
\hline Experimento & & Índices & MAE & RMSE & C \\
\hline \multirow{6}{*}{$\begin{array}{c}16 \text { preditores } \\
(16-16-8-1)\end{array}$} & \multirow{3}{*}{ RNA } & Máx & 0.0712 & 0.0965 & 0.8854 \\
\hline & & Min & 0.1146 & 0.2039 & 0.5775 \\
\hline & & Média & 0.0928 & 0.1344 & 0.7917 \\
\hline & \multirow{3}{*}{ RLM } & Máx & 0.0639 & 0.0787 & 0.9265 \\
\hline & & Min & 0.2375 & 1.7792 & 0.0084 \\
\hline & & Média & 0.0956 & 0.2891 & 0.7729 \\
\hline \multirow{6}{*}{$\begin{array}{c}15 \text { preditores } \\
(15-16-8-1)\end{array}$} & \multirow{3}{*}{ RNA } & Máx & 0.0678 & 0.0889 & 0.9053 \\
\hline & & Min & 0.1581 & 0.7681 & 0.1071 \\
\hline & & Média & 0.0896 & 0.1465 & 0.7850 \\
\hline & \multirow{3}{*}{ RLM } & Máx & 0.0723 & 0.0922 & 0.9086 \\
\hline & & Min & 0.2743 & 2.2341 & 0.0044 \\
\hline & & Média & 0.1098 & 0.4431 & 0.6878 \\
\hline \multirow{6}{*}{$\begin{array}{c}14 \text { predirores } \\
(14-14-7-1)\end{array}$} & \multirow{3}{*}{ RNA } & Máx & 0.0674 & 0.0848 & 0.9054 \\
\hline & & Min & 0.0966 & 0.3030 & 0.4272 \\
\hline & & Média & 0.0813 & 0.1141 & 0.8451 \\
\hline & \multirow{3}{*}{ RLM } & Máx & 0.0728 & 0.0906 & 0.9117 \\
\hline & & Min & 0.0833 & 0.1091 & 0.8361 \\
\hline & & Média & 0.0784 & 0.1000 & 0.8757 \\
\hline \multirow{6}{*}{$\begin{array}{c}13 \text { predirores } \\
(13-14-7-1)\end{array}$} & \multirow{3}{*}{ RNA } & Máx & 0.0671 & 0.0849 & 0.9155 \\
\hline & & Min & 0.1264 & 0.5638 & 0.1613 \\
\hline & & Média & 0.0828 & 0.1219 & 0.8296 \\
\hline & \multirow{3}{*}{ RLM } & Máx & 0.0709 & 0.0881 & 0.9044 \\
\hline & & Min & 0.0866 & 0.1135 & 0.8158 \\
\hline & & Média & 0.0787 & 0.0998 & 0.8730 \\
\hline \multirow{6}{*}{$\begin{array}{c}12 \text { predirores } \\
(12-12-6-1)\end{array}$} & \multirow{3}{*}{ RNA } & Máx & 0.0656 & 0.0855 & 0.9161 \\
\hline & & Min & 0.1022 & 0.3046 & 0.4488 \\
\hline & & Média & 0.0778 & 0.1090 & 0.8565 \\
\hline & \multirow{3}{*}{ RLM } & Máx & 0.0692 & 0.0868 & 0.9082 \\
\hline & & Min & 0.0882 & 0.1142 & 0.8242 \\
\hline & & Média & 0.0779 & 0.0996 & 0.8752 \\
\hline \multirow{6}{*}{$\begin{array}{c}11 \text { predirores } \\
(11-12-6-1)\end{array}$} & & Máx & 0.0656 & 0.0844 & 0.9158 \\
\hline & RNA & Min & 0.0817 & 0.1454 & 0.7763 \\
\hline & & Média & 0.0752 & 0.1012 & 0.8734 \\
\hline & & Máx & 0.0666 & 0.0849 & 0.9080 \\
\hline & RLM & Min & 0.0883 & 0.1182 & 0.8172 \\
\hline & & Média & 0.0796 & 0.1018 & 0.8687 \\
\hline & & Máx & 0.0646 & 0.0823 & 0.9142 \\
\hline & RNA & Min & 0.0816 & 0.1118 & 0.8329 \\
\hline 10 predirores & & Média & 0.0751 & 0.1011 & 0.8729 \\
\hline$(10-10-5-1)$ & & Máx & 0.0699 & 0.0894 & 0.8972 \\
\hline & RLM & Min & 0.0983 & 0.1264 & 0.8119 \\
\hline & & Média & 0.0828 & 0.1055 & 0.8589 \\
\hline & & Máx & 0.0591 & 0.0747 & 0.9317 \\
\hline & RNA & Min & 0.0901 & 0.1297 & 0.8145 \\
\hline 9 predirores & & Média & 0.0748 & 0.1004 & 0.8741 \\
\hline$(9-10-5-1)$ & & Máx & 0.0737 & 0.0901 & 0.8996 \\
\hline & RLM & Min & 0.0955 & 0.1189 & 0.8223 \\
\hline & & Média & 0.0820 & 0.1050 & 0.8599 \\
\hline & & Máx & 0.0681 & 0.0867 & 0.9155 \\
\hline & RNA & Min & 0.0861 & 0.1185 & 0.8180 \\
\hline 8 predirores & & Média & 0.0751 & 0.1018 & 0.8707 \\
\hline$(8-8-4-1)$ & & Máx & 0.0730 & 0.0917 & 0.8956 \\
\hline & RLM & Min & 0.0891 & 0.1210 & 0.8092 \\
\hline & & Média & 0.0820 & 0.1047 & 0.8618 \\
\hline & & Máx & 0.0646 & 0.0907 & 0.9014 \\
\hline & RNA & Min & 0.0850 & 0.1195 & 0.8139 \\
\hline 7 predirores & & Média & 0.0760 & 0.1047 & 0.8625 \\
\hline$(7-8-4-1)$ & & Máx & 0.0782 & 0.0997 & 0.8894 \\
\hline & RLM & Min & 0.0929 & 0.1227 & 0.8043 \\
\hline & & Média & 0.0844 & 0.1086 & 0.8490 \\
\hline
\end{tabular}




\subsection{Seleção Entre os Modelos: Completo, Instantâneo, Máximo e Mínimo}

Como especificado na seção anterior, foi adotada uma nomenclatura personalizada para os experimentos nesta fase do trabalho, que consistiram em modelo completo (utiliza todas as variáveis preditoras selecionadas na etapa anterior de uma única vez), modelo instantâneo, modelo máximo e modelo mínimo que utiliza as variáveis preditoras individualmente.

Observou-se assim que para cada topologia entre os modelos instantâneo, máximo e mínimo não havia grande variação entre as médias dos índices, apresentando valores aproximados entre si. No que se refere a comparação entre os modelos instantâneo, máximo e mínimo com o modelo completo, notou-se que este supera os demais substancialmente, pois os maiores valores médios do Índice de Confiança atingidos pelos modelos individuais não superaram os valores de $C$ atingidos pelo modelo completo, além disso o modelo completo apresenta menores valores de MAE e RMSE.

Ainda analisando o Índice de Confiança foi possível observar que o desempenho dos modelos, tanto para uma quanto para duas camadas escondidas, variou bastante. A tabela 4 apresenta um resumo dos índices observados dos experimentos. A fim de abreviar a tabela, foi adotado o uso de siglas para representar o desempenho do modelo:

- OT: Ótimo (>0.85)

- MB: Muito bom $(0,76$ a 0,85$)$

- BO: $\operatorname{Bom}(0,66$ a 0,75)

- ME: Mediano (0,61 a 0,65)
- SO: Sofrível $(0,51$ a 0,60$)$

- MA: Mau $(0,41$ a 0,50$)$

-PE: Péssimo $(C \leq 0,40)$

Tabela 4. Resumo do Índice de Confiança para topologias com uma e duas camadas escondidas

\begin{tabular}{|c|c|c|c|c|c|c|}
\cline { 2 - 6 } \multicolumn{1}{c|}{} & \multicolumn{2}{c|}{ Valores Médios } & \multicolumn{2}{c|}{ Valores Máximos } & \multicolumn{2}{c|}{ Valores Mínimos } \\
\hline Modelo & Uma de camadas & Duas & Uma & Duas & Uma & Duas \\
\hline Instantâneo & $\mathrm{MB}$ & $\mathrm{BO}$ e MB & MB e OT & MB e OT & BO, ME e MA & BO, ME, SO e PE \\
Máximo & $\mathrm{MB}$ & BO e MB & MB e OT & MB e OT & BO, MB e PE & BO, ME, SO e PE \\
Mínimo & $\mathrm{MB}$ & BO e MB & MB e OT & MB e OT & BO, SO, MA & BO, ME, SO, PE e MA \\
Completo & OT & OT & OT & OT & MB & MB \\
\hline
\end{tabular}

Fazendo a análise dos modelos em termos de tempo médio computacional necessário para a conclusão do treinamento da RNA, obteve-se a tabela 5. Antes mesmo das simulações serem realizadas, esperava-se que o modelo completo levasse mais tempo para convergência que os demais modelos, visto que a quantidade de dados na camada de entrada era maior. Essa suspeita foi corroborada após a mensuração do 
tempo médio computacional, contudo, o modelo completo mostrou ser o mais indicado, pois leva a menores erros e a maior Índice de Confiança. Assim o modelo completo demonstrou ser o mais adequado para estimar a radiação solar e, portanto foi adotado no presente trabalho.

Tabela 5. Tempo médio computacional entre os modelos

\begin{tabular}{|c|c|c|c|c|}
\hline RNA & Completo & Instantâneo & Máximo & Mínimo \\
\hline 1 Camada & $99 \mathrm{~s}$ & $14 \mathrm{~s}$ & $21 \mathrm{~s}$ & $10 \mathrm{~s}$ \\
\hline 2 Camadas & $55 s$ & $23 \mathrm{~s}$ & $24 s$ & $13 \mathrm{~s}$ \\
\hline
\end{tabular}

\subsection{Comportamento do Erro MAE}

Fazendo uso das mesmas topologias utilizadas na subseção anterior e considerando a média do modelo completo, realizou-se então um estudo do comportamento do erro MAE, com o propósito de verificar se haveria a necessidade de acrescentar outras topologias ao estudo.

Assim, foi observado o comportamento do erro MAE para as RNAs de uma e duas camadas escondidas com quantidades diferentes de neurônios em cada uma. Primeiramente foram analisadas as RNAs com uma camada escondida (figura 2).

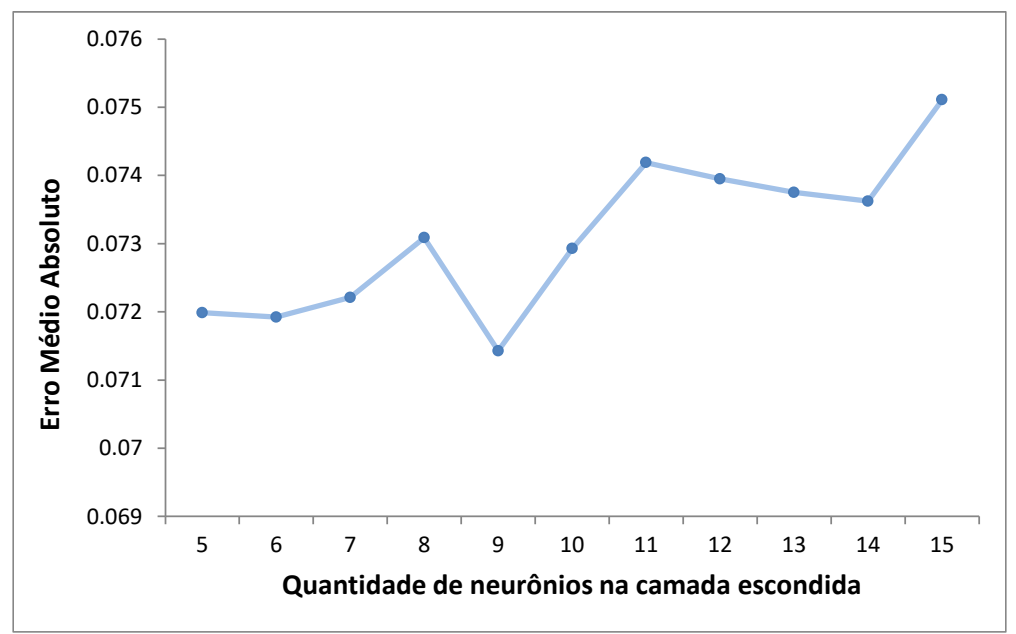

Figura 2. Comportamento do MAE para diferentes quantidades de neurônios na camada escondida

Notou-se que quanto maior a quantidade de neurônios na camada escondida o erro MAE cresceu consideravelmente. E, portanto verificou-se que não haveria a necessidade de treinar outras redes além dessas visto a tendência do erro.

Para redes com duas camadas escondidas, a um primeiro momento, foram treinadas todas as redes apresentadas na figura 3 com exceção da topologia (RNA-9-10-5-1) e até 
esta etapa foi possível analisar a um primeiro momento que o erro MAE diminui, logo em seguida torna a crescer, porém a partir da topologia (RNA-9-8-7-1) não foi possível verificar um comportamento expressivo do erro, impossibilitando afirmar se o mesmo iria aumentar ou diminuir. Por esse motivo foi realizado um teste adicional utilizando a topologia (RNA-9-10-5-1) para investigar qual seria a tendência do erro MAE, a partir daí percebeu-se claramente que o erro voltou a crescer.

Portanto, foi verificado que para as RNAs tanto para uma quanto para duas camadas escondidas, na medida em que se aumenta a quantidade de neurônios nas camadas o erro aumenta. Constatando assim que não há a necessidade de se fazer uso de RNAs com um número muito elevado de neurônios nas camadas internas, visto que o desempenho das redes é aproximado entre si e, além disso, erro e o custo computacional no treinamento aumentam.

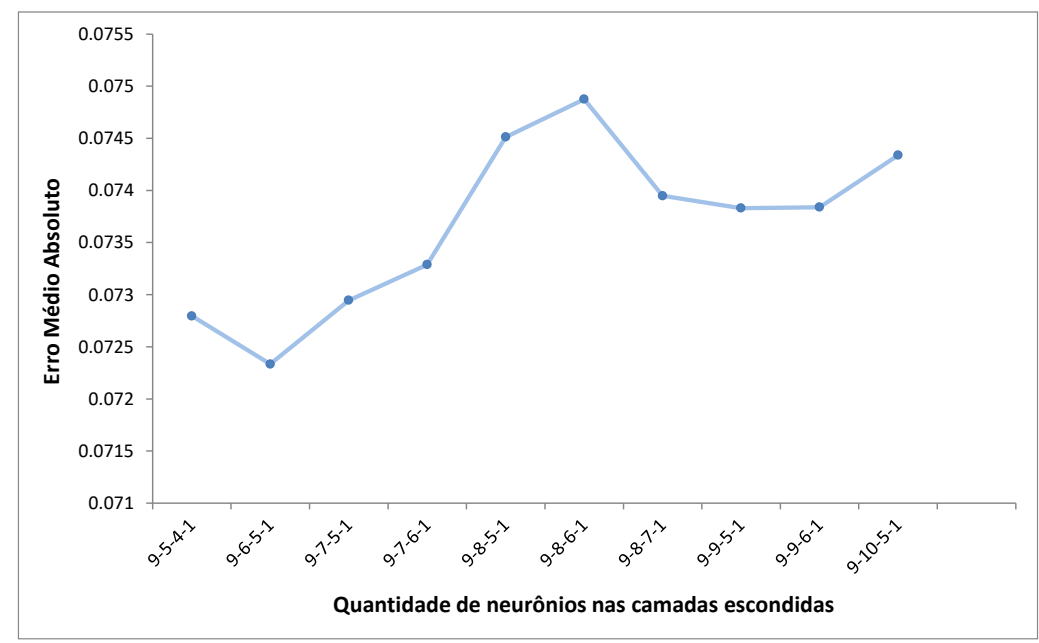

Figura 3. Comportamento do MAE para diferentes quantidades de neurônios nas camadas escondidas

\subsection{Resultados de Irradiação Solar}

Após a seleção do modelo completo, buscou-se fazer uma análise mais detalhada do mesmo a fim de definir qual seria a topologia mais adequada para estimar a radiação solar, para isso foram examinadas as médias das 50 simulações para cada topologia, tanto para uma quanto para duas camadas escondidas. Observou-se que em nenhum caso a média da RLM superou a RNA, tanto para uma quanto para duas camadas. Notouse também que os Índices de Confiança não apresentaram valores muito distantes entre si, quando analisado os casos de valor máximo e mínimo para cada topologia.

Dessa forma as redes que demonstraram melhores desempenhos foram RNA-9-9-1 e RNA-9-6-1 (tabela 7) para uma camada escondida e RNA-9-7-5-1 e RNA-9-6-5-1 
(tabela 8) para duas camadas escondidas. Dentre essas topologias, a que apresentou maiores Índice de Confiança $(C)$ e Coeficiente de Determinação $\left(R^{2}\right)$, além de menores erros MAE, MSE e RMSE foi a RNA-9-9-1. Quando comparada ao modelo de RLM, a RNA mostrou uma redução em termos de Skill de aproximadamente de 12\% do MAE, $14 \%$ do MSE e $7 \%$ do RMSE, em termos de $\mathrm{R}^{2}$ e C apresentou um ganho de $14 \%$ e $15 \%$ respectivamente, conforme a tabela 6 .

Tabela 6. Comparação entre RNA e RLM para previsão de radiação solar

\begin{tabular}{|c|c|c|c|c|c|}
\cline { 2 - 6 } \multicolumn{1}{c|}{} & MAE & MSE & RMSE & $R^{2}$ & C \\
\hline RNA-9-9-1 & 0.071 & 0.009 & 0.095 & 0.853 & 0.888 \\
RLM & 0.081 & 0.011 & 0.102 & 0.830 & 0.868 \\
SKILL & 0.12 & 0.14 & 0.07 & 0.14 & 0.15 \\
\hline
\end{tabular}

Tabela 7. Diferentes topologias para uma camada escondida

\begin{tabular}{|c|c|c|c|c|c|c|c|}
\hline Topologia & & épocas & MAE & MSE & RMSE & $R^{2}$ & c \\
\hline \multirow{3}{*}{$(9-5-1)$} & Máx & 68254 & 0.0641 & 0.0070 & 0.0834 & 0.8953 & 0.9233 \\
\hline & Min & 40783 & 0.0841 & 0.0137 & 0.1172 & 0.7789 & 0.8352 \\
\hline & Média & & 0.0720 & 0.0094 & 0.0968 & 0.8456 & 0.8827 \\
\hline \multirow{3}{*}{$(9-6-1)$} & Máx & 75693 & 0.0613 & 0.0068 & 0.0823 & 0.8995 & 0.9257 \\
\hline & Min & 45576 & 0.0819 & 0.0133 & 0.1151 & 0.7774 & 0.8330 \\
\hline & Média & & 0.0719 & 0.0093 & 0.0961 & 0.8494 & 0.8843 \\
\hline \multirow{3}{*}{$(9-7-1)$} & Máx & 53688 & 0.0628 & 0.0067 & 0.0817 & 0.8968 & 0.9208 \\
\hline & Min & 36257 & 0.0856 & 0.0144 & 0.1201 & 0.7666 & 0.8215 \\
\hline & Média & & 0.0722 & 0.0094 & 0.0966 & 0.8452 & 0.8818 \\
\hline \multirow{3}{*}{$(9-8-1)$} & Máx & 55727 & 0.0633 & 0.0069 & 0.0833 & 0.8893 & 0.9142 \\
\hline & Min & 42704 & 0.0834 & 0.0137 & 0.1169 & 0.7627 & 0.8320 \\
\hline & Média & & 0.0731 & 0.0097 & 0.0980 & 0.8409 & 0.8786 \\
\hline \multirow{3}{*}{$(9-9-1)$} & Máx & 24040 & 0.0628 & 0.0065 & 0.0804 & 0.8998 & 0.9229 \\
\hline & Min & 49744 & 0.0811 & 0.0148 & 0.1217 & 0.7533 & 0.8235 \\
\hline & Média & & 0.0714 & 0.0091 & 0.0947 & 0.8533 & 0.8879 \\
\hline \multirow{3}{*}{$(9-10-1)$} & Máx & 96165 & 0.0615 & 0.0067 & 0.0821 & 0.8932 & 0.9182 \\
\hline & Min & 48777 & 0.0914 & 0.0152 & 0.1233 & 0.7582 & 0.8208 \\
\hline & Média & & 0.0729 & 0.0095 & 0.0972 & 0.8425 & 0.8800 \\
\hline \multirow{3}{*}{$(9-11-1)$} & Máx & 54232 & 0.0683 & 0.0079 & 0.0890 & 0.8774 & 0.9063 \\
\hline & Min & 93757 & 0.0822 & 0.0136 & 0.1167 & 0.7571 & 0.8171 \\
\hline & Média & & 0.0742 & 0.0102 & 0.1004 & 0.8325 & 0.8723 \\
\hline \multirow{3}{*}{$(9-12-1)$} & Máx & 46060 & 0.0668 & 0.0073 & 0.0855 & 0.8793 & 0.9098 \\
\hline & Min & 70725 & 0.0860 & 0.0134 & 0.1157 & 0.7588 & 0.8169 \\
\hline & Média & & 0.0739 & 0.0099 & 0.0994 & 0.8373 & 0.8758 \\
\hline \multirow{3}{*}{$(9-13-1)$} & Máx & 77180 & 0.0639 & 0.0072 & 0.0847 & 0.8910 & 0.9166 \\
\hline & Min & 32861 & 0.0871 & 0.0135 & 0.1162 & 0.7801 & 0.8327 \\
\hline & Média & & 0.0737 & 0.0099 & 0.0990 & 0.8390 & 0.8774 \\
\hline \multirow{3}{*}{$(9-14-1)$} & Máx & 88951 & 0.0633 & 0.0071 & 0.0842 & 0.8837 & 0.9111 \\
\hline & Min & 85266 & 0.0858 & 0.0140 & 0.1183 & 0.7696 & 0.8230 \\
\hline & Média & & 0.0736 & 0.0099 & 0.0991 & 0.8376 & 0.8760 \\
\hline \multirow{3}{*}{$(9-15-1)$} & Máx & 63620 & 0.0601 & 0.0067 & 0.0818 & 0.8879 & 0.9165 \\
\hline & Min & 87117 & 0.0891 & 0.0194 & 0.1391 & 0.6811 & 0.7677 \\
\hline & Média & & 0.0751 & 0.0102 & 0.1007 & 0.8329 & 0.8725 \\
\hline
\end{tabular}


Tabela 8. Diferente topologias para duas camadas escondidas

\begin{tabular}{|c|c|c|c|c|c|c|c|}
\hline Topologia & & n.epocas & MAE & MSE & RMSE & $R^{2}$ & C \\
\hline \multirow{3}{*}{$(9-5-4-1)$} & Máx & 53442 & 0.0591 & 0.0063 & 0.0792 & 0.9014 & 0.9246 \\
\hline & Min & 38530 & 0.0821 & 0.0127 & 0.1125 & 0.7905 & 0.8400 \\
\hline & Média & & 0.0728 & 0.0097 & 0.0979 & 0.8423 & 0.8796 \\
\hline \multirow{3}{*}{$(9-6-5-1)$} & Máx & 43931 & 0.0598 & 0.0061 & 0.0782 & 0.9069 & 0.9294 \\
\hline & Min & 45830 & 0.0813 & 0.0138 & 0.1175 & 0.7589 & 0.8249 \\
\hline & Média & & 0.0723 & 0.0097 & 0.0982 & 0.8424 & 0.8800 \\
\hline \multirow{3}{*}{$(9-7-5-1)$} & Máx & 47310 & 0.0621 & 0.0063 & 0.0795 & 0.9076 & 0.9290 \\
\hline & Min & 52997 & 0.0841 & 0.0132 & 0.1147 & 0.7662 & 0.8290 \\
\hline & Média & & 0.0729 & 0.0097 & 0.0982 & 0.8426 & 0.8807 \\
\hline \multirow{3}{*}{$(9-7-6-1)$} & Máx & 73357 & 0.0633 & 0.0065 & 0.0808 & 0.8832 & 0.9100 \\
\hline & Min & 36628 & 0.0899 & 0.0147 & 0.1212 & 0.7746 & 0.8301 \\
\hline & Média & & 0.0733 & 0.0098 & 0.0987 & 0.8405 & 0.8787 \\
\hline \multirow{3}{*}{$(9-8-5-1)$} & Máx & 39366 & 0.0636 & 0.0077 & 0.0877 & 0.8873 & 0.9137 \\
\hline & Min & 44741 & 0.0905 & 0.0164 & 0.1279 & 0.7346 & 0.8009 \\
\hline & Média & & 0.0745 & 0.0102 & 0.1005 & 0.8331 & 0.8736 \\
\hline \multirow{3}{*}{$(9-8-6-1)$} & Máx & 50477 & 0.0661 & 0.0070 & 0.0838 & 0.8809 & 0.9085 \\
\hline & Min & 59942 & 0.0860 & 0.0156 & 0.1249 & 0.7303 & 0.8061 \\
\hline & Média & & 0.0749 & 0.0104 & 0.1015 & 0.8292 & 0.8708 \\
\hline \multirow{3}{*}{$(9-8-7-1)$} & Máx & 97294 & 0.0673 & 0.0070 & 0.0838 & 0.8940 & 0.9218 \\
\hline & Min & 36781 & 0.0810 & 0.0150 & 0.1225 & 0.7333 & 0.7982 \\
\hline & Média & & 0.0739 & 0.0100 & 0.0998 & 0.8366 & 0.8767 \\
\hline \multirow{3}{*}{$(9-9-5-1)$} & Máx & 43900 & 0.0596 & 0.0063 & 0.0792 & 0.8989 & 0.9225 \\
\hline & Min & 63025 & 0.0856 & 0.0150 & 0.1226 & 0.7463 & 0.8098 \\
\hline & Média & & 0.0738 & 0.0100 & 0.0995 & 0.8364 & 0.8765 \\
\hline \multirow{3}{*}{$(9-9-6-1)$} & Máx & 81172 & 0.0632 & 0.0070 & 0.0834 & 0.8935 & 0.9187 \\
\hline & Min & 72834 & 0.0784 & 0.0280 & 0.1672 & 0.5478 & 0.7060 \\
\hline & Média & & 0.0738 & 0.0103 & 0.1008 & 0.8314 & 0.8734 \\
\hline \multirow{3}{*}{$(9-10-5-1)$} & Máx & 30924 & 0.0601 & 0.0065 & 0.0806 & 0.8986 & 0.9222 \\
\hline & Min & 25855 & 0.0843 & 0.0155 & 0.1243 & 0.7516 & 0.8276 \\
\hline & Média & & 0.0743 & 0.0101 & 0.1000 & 0.8342 & 0.8746 \\
\hline
\end{tabular}

A figura 4 apresenta a dispersão dos valores estimados $(X)$ pelo método e os valores observados (O) pela estação Ecologia Agrícola. As linhas cinza possuem coeficientes angulares unitários e passam pelas origens dos gráficos, elas denotam os casos onde as previsões seriam perfeitas, ou seja, os valores estimados se igualam aos valores observados. $(X=0)$. Na figura 4 encontram-se também as retas que representam 0 comportamento geral das previsões (pretas), os dados estimados pela RNA em vermelho e pela RLM em azul.

Observa-se nos diagramas de dispersão da figura 4 que a linha de tendência do modelo de RNA aproxima-se consideravelmente da linha de previsão perfeita, ao passo que a linha de tendência do modelo de RLM encontra-se abaixo da linha de previsão perfeita, o que indica que este modelo estima intensidades de radiação menores do que as observadas pela estação, ou seja, os dados estimados por RLM subestimam a radiação solar. 

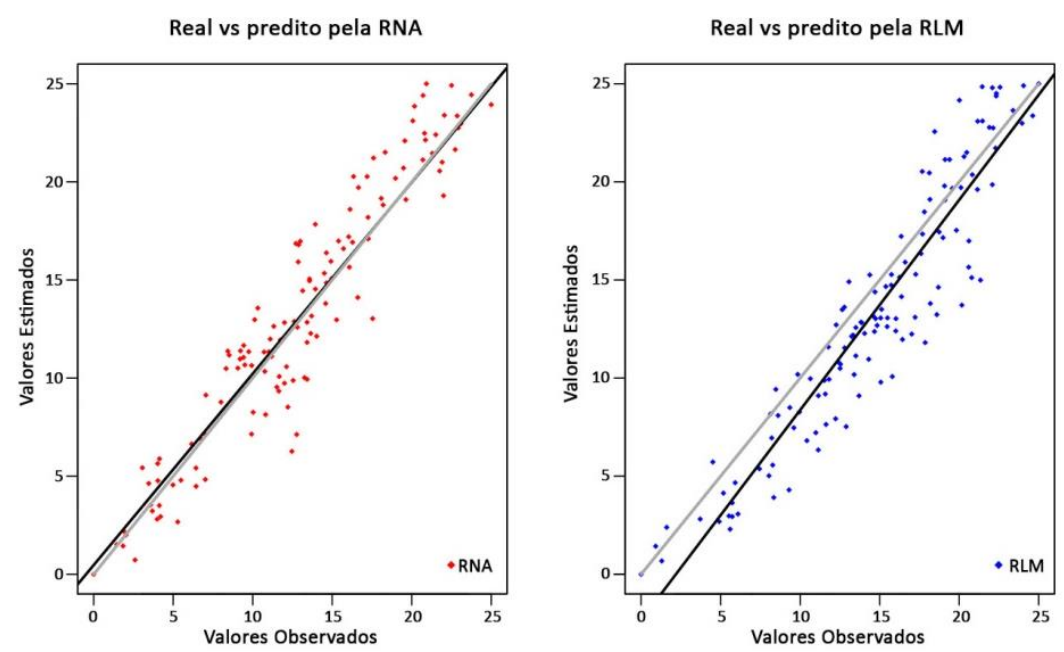

Figura 4. Diagrama de dispersão dos valores estimados de radiação solar do modelo RNA-9-9-1 e de RLM

É apresentada na figura 5 a arquitetura da RNA que demonstrou melhor resultado no modelo proposto. Interessante observar que a rede que demonstrou melhor desempenho consta com apenas uma camada interna de neurônios ocultos. Resultado semelhante foi encontrado por Fiorin et.al. (2011), que em seu estudo utilizou o algoritmo de Levenberg-Marquardt, a fim de analisar a incidência de radiação solar em São Martinho da Serra no Rio Grande do Sul. Os dados de irradiação solar foram coletados na estação de superfície pertencentes à rede SONDA. Como resultado obteve que as redes neurais podem fornecer estimativas confiáveis para avaliação da disponibilidade de energia solar, apresentando também melhor desempenho em comparação a outras técnicas estatísticas utilizadas e inclusive concluiu também que uma camada oculta é suficiente para gerar uma boa estimativa.

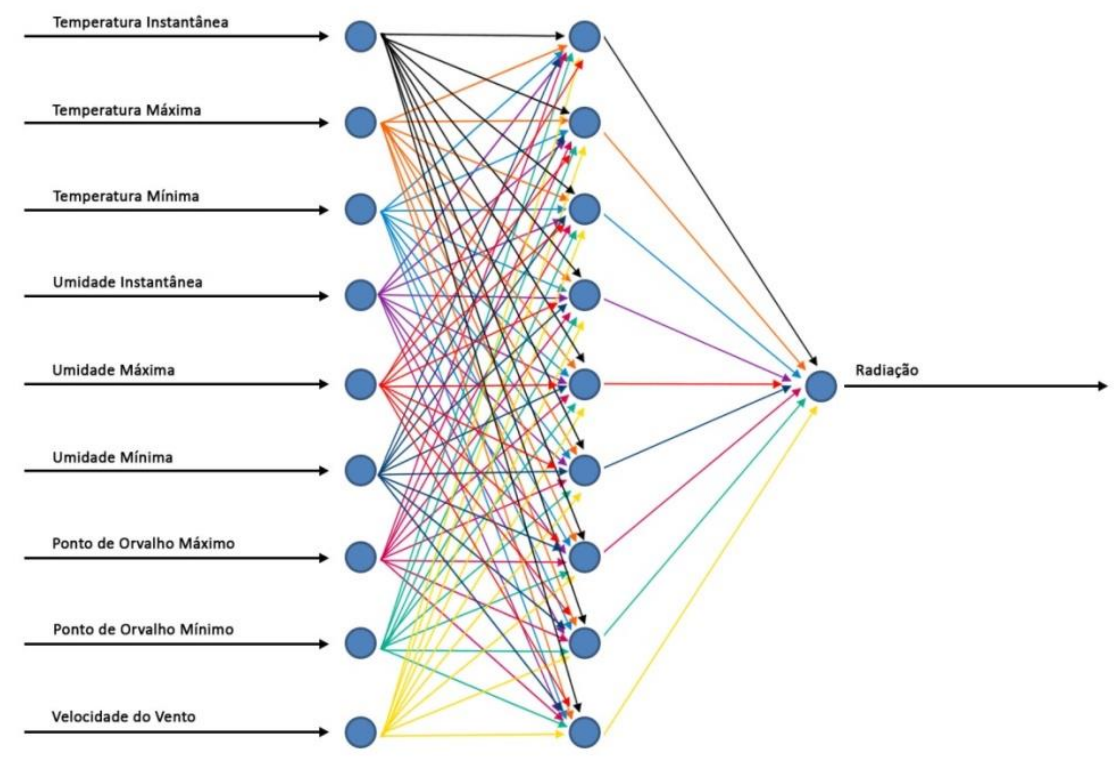

Figura 5. Arquitetura da rede MLP proposta 


\section{CONSIDERAÇÓES FINAIS}

O objetivo do presente estudo foi alcançado com êxito, que foi avaliar a aplicabilidade de Redes Neurais Artificiais (RNAs) do tipo Múltiplas Camadas (MLP) para estimar a incidência de radiação solar em Seropédica, concluindo que este método computacional é apropriado para tal fim, pois é um recurso que gera boas estimativas com pequenos erros. Além disso, foi possível comprovar também que o software $\mathrm{R}$ com o uso do algoritmo resilient backpropagation é uma boa ferramenta para a proposta do presente estudo.

No que diz respeito à comparação do desempenho entre as RNAs e os modelos de Regressão Linear Múltipla (RLM), notou-se que o método de Redes Neurais Artificiais superou a RLM, contudo não apresentaram ganhos significativos frente a estas. Acreditase que a similaridade entre os métodos se dá em virtude do período relativamente curto de coleta de dados.

Foi possível observar também que para estimar a radiação solar não se faz necessário o uso de todas as variáveis disponibilizadas pelo Instituto Nacional de Meteorologia através da estação Ecologia Agrícola. Assim, as variáveis consideradas foram temperatura (instantânea, máxima, mínima), umidade (instantânea, máxima, mínima), ponto de orvalho (máximo, mínimo), velocidade do vento.

$\mathrm{Na}$ análise entre os modelos: completo, instantâneo, máximo e mínimo, comprovouse que, embora o tempo computacional gasto pelo modelo completo seja maior do que os outros modelos, ele leva a melhores resultados.

Para cada topologia de RNA utilizada no trabalho foram repetidas 50 simulações e ao analisar as médias dos experimentos realizados das RNAs com uma e duas camadas escondidas, obteve-se como resultado que uma camada escondida é suficiente para gerar boas estimativas de radiação solar, destacando-se a topologia RNA-9-9-1 que apresentou um ótimo desempenho de Índice de Confiança $(\mathrm{C})$ médio de $88 \%$ e coeficiente de determinação médio $(\mathrm{R} 2)$ de $85 \%$. Dentre as 50 simulações da topologia RNA-9-9-1 o maior Índice de Confiança (C) alcançado foi de 92\% apresentando também um ótimo desempenho. Concluindo que não é viável investir em redes muito grandes tendo em vista que os resultados são muito próximos à redes com menos camadas e neurônios ocultos, além disso, notou-se que em redes com muitas camadas e neurônios ocultos o erro e o custo computacional no treinamento aumentam. 
Finalmente, tendo em vista a tendência atual por formas de geração de energia que menos agridam ao meio ambiente, e que nos últimos anos a energia solar fotovoltaica tem se mostrado uma opção promissora, o Brasil vive um momento de oportunidades, pois possui um território propício para o aproveitamento desse tipo de energia. O município de Seropédica localizado no estado do Rio de Janeiro possui uma vasta área onde poderia ser aproveitada para instalação de painéis solares, a própria Universidade Federal Rural do Rio de Janeiro, situada no município, dispõe de uma ampla área que também poderia ser utilizada. Dessa forma, caso o Brasil continue desenvolvendo sua capacidade de geração fotovoltaica fica em evidência, neste trabalho, o elevado potencial da região de Seropédica para investimentos desta natureza.

\section{AGRADECIMENTO}

O presente trabalho foi realizado com apoio da Coordenação de Aperfeiçoamento de Pessoal de Nível Superior - Brasil (CAPES) - Código de Financiamento 001, e assim, deixo o meu agradecimento pelo auxílio financeiro da bolsa de mestrado (Processo 23038.013648/2018-51).

\section{REFERENCIAS}

ABDALA, P.J.P. Energia Solar e Eólica. Ponta Grossa (PR): Atena Editora; v. 1. 2019.

BENTLEY, R.W., Energy Policy 30, 189, 2002.

CASTRO, J.O; TEIXEIRA, R.O; OLIVEIRA, A.D E CARVALHO, A. G. Comportamento de Coleópteros Degradadores de Madeira em Plantio de Mimosa caesalpiniaefolia (Sabiá) Seropédica, RJ. XIII Encontro Latino Americano de Iniciação Científica e IX Encontro Latino Americano de Pós-Graduação - Universidade do Vale do Paraíba, 2009.

COSTA, R. C. Modelos Preditivos de Velocidade de Vento para Sistemas Eólicos Baseados em Redes Neurais Artificiais. Monografia, UFPB, João Pessoa, 2016.

COUTINHO, E. R. Aplicação de Técnicas de Inteligência Computacional no preenchimento de Falhas de Séries Temporais Climatológicas. Dissertação. UFRRJ, Seropédica, 2014.

E. R. SILVA, R. M.; DELGADO, A. R. S. Utilização de Técnicas de Inteligência Computacional na Predição de Dados Meteorológicos. Revista Brasileira de Meteorologia, v. 31, n. 1, p. 24-36, 2016.

DESHMUKH, R. P.; GHATOL, A. A. Comparative Study of Temporal Neural Networks for Short Term Flood Forecasting. International Journal of Computer Applications, v. 5, n. 12, p. 24-28, 2010. 
FIORIN, D.V., MARTINS, F.R, SCHUCH, N.J., PEREIRA, E.B. Aplicações de Redes Neurais e Previsões de disponibilidade de Recursos Energéticos Solares. Revista Brasileira de Ensino de Física, v. 33, n. 1, 1309, 2011.

FONSECA, J. S.; MARTINS, G. A.; TOLEDO, G. L. Estatística Aplicada. Ed. 2, p. 267. 2012.

GUARNIERI, R.A., Emprego de Redes Neurais Artificiais e Regressão Linear Múltipla no Refinamento das Previsões de Radiação Solar do Modelo Eta. Dissertação de Mestrado, INPE, São José dos Campos, 2006.

HEINEMANN, D., LORENZ, E. and GIRODO, M., in: Proc. International Workshop on Solar Resource from the Local Level to Global Scale in Support to the Resource Management of Renewable Electricity Generation. Institute for Environment and Sustainability, Joint Research Center, Ispra. 2004.

IBGE - Instituto Brasileiro de Geografia e Estatística. v4.3.16.1 Brasília: IBGE. 2017. Disponível em <https://www.ibge.gov.br/> acesso em 31/01/2019.

IPEA - Instituto de Pesquisa Econômica Aplicada. Caderno ODS: Assegurar o Acesso Confiável, Sustentável, Moderno e a Preço Acessível à Energia para Todos. 2019. Disponível em $<$ http://www.ipea.gov.br/portal/index.php?option=com_content\&view=article\&id=34715 \&ltemid $=444>$ Acesso em 10/05/2019.

INMET, Instituto Nacional de Meteorologia. BDMEP - Banco de Dados Meteorológicos para Ensino e Pesquisa. Disponível em: <http://www.inmet.gov.br/portal/> Acesso em $01 / 02 / 2019$

MENDES, I.A., REZENDE, R.A.D., NASCIMENTO, T.H.F., SILVA, J.S.F. e SILVA, O. F. A Utilização das Redes Neurais Artificiais na Previsão de Radiação Solar Global. Congresso Técnico Científico da Engenharia e da Agronomia. Belém - PA 2017.

MESINGER F., in: Proceedings of ICTP Regional Weather Predictability and Modeling Workshop, CPTEC/INPE, São José dos Campos 2005. Disponível em ftp://ttp1.cptec.inpe.br/etamdl/Download/model/EtaGuide. 2008.8.pdf. Acesso em $21 / 02 / 2018$

PERBONI, A; FRIZZONE, J.A.; CAMARGO, A. P. Artificial Neural Network Based Equation to Estimate Head Loss Along Dripp Irrigation Laterals. Revista Brasileira de Agricultura Irrigada v.8, №. 2, p. 77 - 85, 2014

PEREIRA, E.B., MARTINS, F.R., GONÇALVES, A.R; COSTA, R.S.; LIMA, F.J.L.; RUTHER, R.; ABREU, S.L.;TIEPOLO, G.M.; PEREIRA, S.V.; SOUZA, J.G. Atlas Brasileiro de Energia Solar: Instituto Nacional de Pesquisas Espaciais, São José dos Campos, SP. 2ed. 88p. 2017.

PEZZOPANE, J.E. M.; CASTRO, F.S.; PEZZOPANE, J.R.M.; CECÍLIO, R.A. AGROMETEOROLOGIA: Aplicações para o Espírito Santo. Alegre, ES: CAUFES. 2012. 
PINHEIRO, E.; LOVATO, A.; RÜTHER, R. Aplicabilidade de Redes Neurais Artificiais para Análise de Geração de Energia de um Sistema Fotovoltaico Conectado a Rede Elétrica. Revista Brasileira de Energias Renováveis. v.6, n.5, p. 875-892, 2017.

PMS - Prefeitura Municipal de Seropédica. Dados Gerais. 2019. Disponível em <http://www.seropedica.rj.gov.br/> Acesso em 31/01/2019. 